\title{
Survivorship in Danish women surgically treated for gynecological cancer - The impact of postoperative rehabilitation
}

\author{
Lene Seibaek, Lone Kjeld Petersen \\ Department of Gynecology and Obstetrics, Aarhus University Hospital, Denmark
}

Received: September 2, 2016

DOI: $10.5430 / \mathrm{cns} . v 4 \mathrm{n} 4 \mathrm{p} 66$

\author{
Accepted: November 16, $2016 \quad$ Online Published: December 1, 2016 \\ URL: http://dx.doi.org/10.5430/cns.v4n4p66
}

\begin{abstract}
Objective: As cancer treatments improve and the number of survivors increase, rehabilitation and survivorship issues have become an increasingly important aspect of cancer care. Presently there is little evidence describing how to address patients survivorship needs. On this ground a cancer rehabilitation program that matches the needs of women surgically treated for early stage gynecological malignancies and their relatives, was developed and tested.

Methods: The rehabilitation program was conducted by a multidisciplinary team and consisted of lectures, physical training and group support sessions. The program consisted of four three-hour sessions held weekly over four weeks. The program was evaluated by two questionnaires completed by the patients, the Short Form 36 and Sense of Coherence, pre and post intervention. Results: Twenty-one courses were held with 371 participants: 217 patients (participation rate 35\%) and 154 relatives. The patients' age ranged between $22-85$ years. Of these, $61 \%$ had been operated for localized stages of endometrial cancer, and $27 \%$ for local stages of cervical cancer. The questionnaires demonstrated an increase in all elements of the physical and mental health components during the study period. However, general health was the only component that surpassed the level recorded for healthy women.

Conclusions: The evaluation demonstrated that the patients experienced a positive personal outcome due to participation in the program. This finding was however not fully retrieved in the questionnaire results. Informal feedback revealed that the program provided clinicians with significant patient perspectives on survivorship issues in gynecological cancer care. Most patients completed their surgical treatment within a few days, and were considered clinically cured. To these patients and their relatives, the rehabilitation program represents a combined supportive self-care and specialized shared care intervention, which is feasible in combination with the pre-existing follow-up.
\end{abstract}

Key Words: Group sessions, Physical training, Women, Relatives, Clinical pathway

\section{INTRODUCTION}

In this article, we present the prospective, long term evaluation of a postoperative rehabilitation program designed to match the needs of women surgically treated for early stage gynecological cancer. The evaluation applies a patient per- spective in terms of the participants' general health, coping capacity, and personal outcome of attending. In addition, the organizational and clinical experiences of running the program over a decade will be described.

Long-term survivorship issues of cancer patients are a well

\footnotetext{
${ }^{*}$ Correspondence: Lene Seibaek; Email: Leneseib@rm.dk; Address: Department of Gynecology and Obstetrics, Aarhus University Hospital, Palle Juul-Jensens Boule-vard 99, DK-8200 Aarhus N, Denmark.
} 
recognised concern. ${ }^{[1-3]}$ As cancer treatment improves and inpatient hospitalisation shortens, the postoperative rehabilitation therefore constitutes an increasingly important multidisciplinary element of the overall cancer treatment trajectory. ${ }^{[3]}$ Generally, women who are treated for localised gynecological cancer diseases with surgery alone have a very good prognosis. ${ }^{[4]}$ It is anticipated that for these cancer survivors and their relatives, going through a successful postoperative rehabilitation process will support their future general health and health-related quality of life.

Rehabilitation is defined as a goal-oriented, cooperative process involving an individual, her relatives, and professionals over a specific period of time. The concept originates from The World Health Organisation's International Classification of Functioning, Disability, and Health, ${ }^{[5]}$ and combines biological, psychological, and cultural perspectives on health in relation to rehabilitation. Within this theoretical framework, the individual woman is at the same time a physical body, an individual person, and a participant.

Due to the general increase in incidence and survival of cancer diseases in the Western world, cancer survivorship issues have been subject to an increasing focus in the organisation of treatment and care, during the last decade. ${ }^{[2]}$ In relation to cancer, rehabilitation aims to reduce the physical, psychological, and social consequences of the malignant disease and its treatment for patients as well as their families. In gynecological cancers, prognosis and treatment trajectory depends on the type and stage of disease and pre-existing comorbidities. The rehabilitation process can therefore be heterogeneous as survivorship needs vary substantially according to type and stage, and from one woman to another. The rising body of evidence however demonstrates a substantial need for post treatment rehabilitation and addressing female survivorship issues in general, such as psychosocial and sexual needs, femininity, infertility, fatigue and fear of recurrence. ${ }^{[6,7]}$

In the Western world, women who are diagnosed with low stage gynecological malignancies have a good prognosis with a cancer specific five-year survival exceeding 90\%. Still, approximately $20 \%$ of these bio-medically cured women seem to continue to perceive themselves as cancer patients, regardless of the time that has passed since surgery, of their age, and of the fact that most of them have finished follow-up visits years earlier. ${ }^{[8]}$ Furthermore, some of those who actually do experience side effects seem to neither look for, nor receive, any treatment of their condition. Thus, a lack of knowledge and a lack of health care services in relation to postoperative rehabilitation and late effects following fasttrack gynaecological cancer surgery were identified. On this ground, a rehabilitating intervention for women who under- went surgery for low-stage localised gynaecological cancer diseases and their relatives was developed. The aim of the study was to prospectively evaluate the impact of postoperative rehabilitation in gynaecological cancer by measuring the participants' general health, coping capacity, and personal outcome of attending.

\section{METHOD}

\subsection{Participants}

Women who underwent fast-track surgery for localised stages of any gynecological malignancy at a national centre for surgical treatment of gynaecological malignancies in Denmark were included in the study. Women who were unable to read or write Danish, suffered from mental illness, required adjuvant chemotherapy or radiation, or had an additional cancer diagnosis were excluded.

\subsection{Study design}

The design of the postoperative rehabilitation program was based on the existing knowledge of patient education programs. ${ }^{[9-11]}$ The program consisted of four sessions, held once per week with each session lasting three hours. It was facilitated by nurse specialists from within the surgical department, who gave lectures and served as coordinators. Sessions were held in facilities situated at the cancer centre. Each session provided a combination of lectures, physical training and supportive group sessions delivered by a multidisciplinary team of healthcare professionals and counsellors (see Table 1). Relatives were invited to attend the first session of the program including a session about being a relative of a person with cancer. During sessions, the participants were invited to share personal experiences and tell their illness history. The postoperative rehabilitation program was piloted between 2004 and 2006. As the preliminary results showed significant improvements in the participants' coping capacity, vitality and physical functioning, the programs were continued. ${ }^{[12]}$ During the study period (2004-2014), a total of 21 courses were held. With the exception of a few small alterations, the courses maintained their original structure in providing a combination of information, physical training, and supportive group sessions (see Table 1).

\subsection{Assessment tools}

The postoperative rehabilitation program represented a complex intervention. It was therefore monitored quantitatively in terms of the effect on general health and coping capacity before and one year after attending, as well as qualitatively by investigating the personal impact of participation. Baseline evaluations via questionnaires took place upon enrolment into the program, with secondary evaluation one year later. 
Table 1. Overview of the elements in the survivorship care program (duration $3 \mathrm{hrs} 30 \mathrm{~min}$ )

\begin{tabular}{|c|c|c|c|}
\hline Session & Elements & & \\
\hline Session no. 1 & $\begin{array}{l}\text { Gynecological cancer } \\
\text { - the diseases and their treatment } \\
\text { (Chief surgeon) }\end{array}$ & $\begin{array}{l}\text { Activity: Relaxation and exercise } \\
\text { (Physiotherapist) } \\
\text { Being close to a person with cancer } \\
\text { - for relatives } \\
\text { (Nurse specialist) }\end{array}$ & $\begin{array}{l}\text { Group session - mixed } \\
\text { (Nurse specialist) }\end{array}$ \\
\hline Session no. 2 & $\begin{array}{l}\text { Activity: The abdominals and the pelvic floor } \\
\text { - training after surgery } \\
\text { (Physiotherapist) }\end{array}$ & $\begin{array}{l}\text { Cancer and life } \\
\text { (Psychotherapist) }\end{array}$ & $\begin{array}{l}\text { Group session } \\
\text { (Nurse specialist) }\end{array}$ \\
\hline Session no. 3 & $\begin{array}{l}\text { Activity: Five rhythms } \\
\text { - workout for body and soul } \\
\text { (Body therapist) }\end{array}$ & $\begin{array}{l}\text { Identity, body image and sexuality } \\
\text { (Sexologist) }\end{array}$ & $\begin{array}{l}\text { Group session } \\
\text { (Nurse specialist) }\end{array}$ \\
\hline Session no. 4 & $\begin{array}{l}\text { Activity: Five rhythms } \\
\text { - workout for body and soul } \\
\text { (Body therapist) }\end{array}$ & $\begin{array}{l}\text { Towards a new everyday life } \\
\text { (Nurse specialist) }\end{array}$ & $\begin{array}{l}\text { Group session } \\
\text { (Nurse specialist) }\end{array}$ \\
\hline
\end{tabular}

Two questionnaires that were previously validated in a Danish context were used to survey the study period. To minimize recall bias, the evaluation took place prospectively. The Short Form 36 (SF-36) questionnaire was chosen to survey general health, because it estimates self-assessed general health status in adult individuals. It is a 36 -item questionnaire, where health status is defined within eight sub-areas: "physical functioning", "limitations due to physical conditions", "pain", "general health", "energy/tiredness", "social functioning", "limitations due to mental conditions", and "mental well-being". [13] Scores range from 0 to 100, in witch higher scores represen better health status. To survey the individual coping capacity, the Sense of Coherence questionnaire "SOC" was applied. ${ }^{[14]}$ This questionnaire evaluates personal resources for coping with difficult life situations in terms of being able to manage tension, to find solutions, and to mobilise personal resources. It is a 29 -item questionnaire, each of which contains seven possible answers, and has a range of the means from 100 to 165 , with higher scores representing better coping. Both questionnaires were filled out in two questionnaire rounds by each participant. The first time in relation to the first session, and second time one year later, where the questionnaires were send to the respondents by mail.

\subsection{Data, statistics and text analyses}

Data entry was carried out by a data manager, and the statistical software package Stata 10 was used in the analyses. ${ }^{[15]}$ To match the purpose, data are reported descriptively in numbers, percentages, mean values, medians and range. Data were analysed comparatively, using paired $t$-tests to establish pre- and post differences between the study groups. Since one of the purposes of the study was to measure the difference between time points, the findings were presented with
$95 \%$ confidence intervals $(\mathrm{CI})$. In a single indicator, where the overlapping in CI was marginal, a two-sided $p$-value for the $t$-distribution was applied to determine significance. After having completed the postoperative rehabilitation program, the women filled in a 12-item, open-ended course evaluation form, which addressed two main focus areas: the personal outcome of participating in the program, and the content, timing, and facilities. These patient statements underwent thematic text analysis.

\subsection{Ethics}

The study was approved by the Danish Data Protection Agency, file no. 2001-41-1603 \& 2004-41-4223. According to the Danish Regional Committee on Biomedical Research Ethics, the study needed no further approvals. All procedures were in accordance with the ethical standards of the Danish Regional Committee on Biomedical Research Ethics and the 1964 Helsinki declaration. The women received both oral and written information about the postoperative rehabilitation program during their hospitalization and in relation to final diagnosis, and were invited to participate by mail, one to three months after their surgery.

\section{RESULTS}

During the study period, a number of 21 postoperative rehabilitation programs had a total of 371 participants: 217 patients (in the following referred to as women) and 154 relatives. As 618 women had been invited, the participation rate was on average $35 \%$, with age distribution from 22 years to 85 years (median 58). The relative participation rate was $71 \%$ (see Table 2), comprising a majority of male partners (77\%). Thus, participants per course were on average ten female patients of varying age, and seven relatives. 
The majority of the women had undergone fast-track surgery for localised stages of endometrial cancer $(61 \%)$ or cervical cancer (27\%) (see Table 2). At the beginning of the study period, surgery was performed by laparotomy with either abdominal hysterectomy and bilateral salpingo-ooforectomy, or abdominal radical hysterectomy and pelvic lymph node resection. Pelvic lymph node resection in patients with high risk endometrial cancer was introduced in 2008. Since 2012 laparoscopy with or without robotic assistance are the main treatment modalities in both endometrial and cervical cancer.

Table 2. Distribution of participants and diagnosis 2005-2014

\begin{tabular}{ll}
\hline Distribution of participants & $\mathbf{n}$ \\
\hline - Invited patients & 618 \\
- Participating patients & 217 \\
- Participating relatives & 154 \\
- Participants total & 371 \\
\hline Distribution of diagnosis & $\mathbf{n}$ \\
\hline - Ovarian cancer & 9 \\
- Endometrial cancer & 133 \\
- Cervical cancer & 59 \\
- Vulva cancer & 7 \\
- Other gyn. cancer & 9 \\
\hline
\end{tabular}

\subsection{Questionnaire results}

A total of 202 pairs of SF36 and SOC questionnaires were collected in two questionnaire rounds. Subsequently three pairs of questionnaires were excluded due to $>10 \%$ incomplete answers. Of the remaining 199 pairs of questionnaires, $107(54 \%)$ were answered in relation to the first session and $92(46 \%)$ were answered after one year. The distribution in age and diagnoses in the respondent group proved similar to the total group of participants.

Regarding the individual coping capacity (SOC), mean ratio scores demonstrated an increase during the study period. However the increase proved non-significant measured by 95\% CI (see Table 3).

Regarding the self-assessed general health status (SF 36), increase in all elements of both physical and mental health took place during the study period. In the physical component, this increase was only significant measured by $95 \%$ $\mathrm{CI}$ in relation to Physical Role, whereas the improvements of Physical functioning, Bodily Pain and General Health were non-significant. In the mental component the increase was significant in relation to Vitality, Social Functioning, and Emotional Role, whereas a two-sided $p$-value for the t-distribution in Mental Health on 0.27 demonstrated that this improvement was actually non-significant (see Table 3 ).

\subsection{Personal evaluations}

Between 2008 and 2013, evaluation forms were collected from 127 of 191 women (response rate 64\%). The thematic analysis of the personal outcome of attending revealed that on a personal level the programme had initiated rehabilitation. One woman exemplified: "The cancer diagnosis has been a great sorrow, but at the same time my cure has been a great miracle - the rehabilitation programme has made it possible for me to cope with both aspects." The personal outcome addressed health promotion in a broad sense: "I feel more healthy and normal after having attended the course." The women stressed that future patients should be encouraged to participate: "My first reaction [to the invitation] was that I was doing well, but in retrospect I realize that I actually really needed this."

Table 3. The results from the two questionnaire rounds SOC and SF36

\begin{tabular}{|c|c|c|c|c|}
\hline & \multicolumn{2}{|c|}{ First session $(n=107)$} & \multicolumn{2}{|c|}{ After a year $(n=92)$} \\
\hline & Mean value & $95 \% \mathrm{CI}$ & Mean value & $95 \% \mathrm{CI}$ \\
\hline Sense of Ccoherence (SOC) & 148 & $145-152$ & 152 & $147-156$ \\
\hline \multicolumn{5}{|l|}{ Short Form 36 (SF36) } \\
\hline \multicolumn{5}{|l|}{ Physical component } \\
\hline - Physical Functioning (PF) & 84.5 & $81.0-88.0$ & 87.6 & $84.0-91.2$ \\
\hline - Role Physical (RP) & 63.2 & $55.4-71.0$ & 76.4 & $68.8-83.9$ \\
\hline - Bodily Pain (BP) & 81.4 & $77.4-85.5$ & 84.3 & $80.1-88.4$ \\
\hline - General Health $(\mathrm{GH})$ & 75.9 & $72.1-79.8$ & 79.2 & $75.8-82.7$ \\
\hline \multicolumn{5}{|l|}{ Mental component } \\
\hline - Vitality (V) & 63.3 & $59.4-67.2$ & 69.0 & $64.3-73.6$ \\
\hline - Social Functioning (SF) & 84.7 & $80.8-88.6$ & 89.8 & $86.1-93.6$ \\
\hline - Role Emotional (RE) & 69.4 & $62.3-76.6$ & 77.5 & $69.7-85.3$ \\
\hline - Mental Health (MH) & 77.0 & $73.8-80.2$ & $80.8^{*}$ & $77.0-84.6$ \\
\hline
\end{tabular}

\footnotetext{
${ }^{*}$ The two sided $p$-value for the $t$-distribution on 0.264 determined this sub-area non-significant
} 
The fact that relatives were invited to attend the first session was regarded as a valuable recognition of their efforts and needs. The invitation itself seemed to initiate mutual involvement in terms of their shared reflections concerning the impact of the disease and treatment on their family life and future relation: "My husband and I have talked a lot, and resolved things we might not otherwise have been able to cope with."

Lectures concerning gynecological cancer diseases and psychological reactions, the group sessions with peers, and the physical activity sessions were evaluated to create synergy, also on a personal level: "The exercises established further contact between us and transformed us into something special - not just a group of cancer sufferers sitting at a table.'

\subsection{Program evaluations}

The women estimated the ideal timing for attending to be approximately two months after their surgery, when physical recovery allowed increasing levels of physical activity, and personal reflections and psychosocial reactions still impacted daily life. Continued presence of experienced cancer nurses with insight into the various elements of the treatment trajectory was positively evaluated, as this meant that individual reactions and needs were followed up during the course. However, some specified that they found issues concerning intimacy and sexuality less suited for a group session, and would have preferred this topic to be dealt with on an individual bases, for instance during regular clinical follow-up.

\section{Discussion}

The aim of this study was to prospectively evaluate the effect of attending a postoperative rehabilitation program for women, solely surgically treated in fast-track regimens for localised stages of gynaecological cancer. The overall results have illustrated a benefit for both patient and family through provision of specialised, postoperative rehabilitation among women, surgically treated for gynaecological cancer. Based on the evaluations, postoperative rehabilitation should be initiated at the end of the postoperative period, approximately eight weeks after the surgery.

Although the description of the study group is limited, prominent characteristics are firstly the range in age distribution among the women in need, and secondly the prevalent representation of women treated for endometrial cancer (see Table 2). It represents a challenge to match the sessions to a heterogeneous group in terms of age and diagnosis, in order to make the program fully relevant to the participants. On the other hand the findings demonstrate that the need of postoperative rehabilitation does not seem to decrease with age. We find the existing number of participants appropriate, and advice to increase the number of courses rather than the number of participants, if required. Programs tailored for those women who are treated for endometrial cancer alone, or programs targeting women in a certain age, should furthermore be considered.

The questionnaire response rate was moderate of respectively $54 \%$ and $46 \%$, resulting in quite broad confidence intervals especially in the second questionnaire round. In addition, a lack of a genuine control group made comparison difficult. The results must therefore be interpreted with caution, and further studies might include screening in a control group for problems targeted in the rehabilitation program. Still, prospective, repeated measurements of the General Health (SF36) and the Coping capacity (SOC) provided significant information concerning the nature of the healing process that women go through the first year after fast-track surgery, if they were offered specialised rehabilitation on a shared care level. As participation in the postoperative rehabilitation program was optional, the women represented those who reached out for support. It is unknown whether they also represented those who experienced the most severe problems, and worth noting that a constant level in coping capacity scores (SOC) demonstrated the presence of a quite stable and robust coping capacity among the participating women. ${ }^{[16]}$ Still, the results have indicated that the psychosocial impact of the cancer disease and treatment may exceed one year post treatment, also for those women who are fully cured and have an intact coping capacity, and despite the intervention, which sustains findings by Sekse et al. ${ }^{[12]}$

The questionnaire indicators concerning Physical Role, and Vitality, Social Functioning, and Emotional Role respectively were significantly improved one year after treatment. As the women from a medical perspective were cured, we found it relevant to compare these results with similar data obtained in a comparable population of Danish women. ${ }^{[17]}$ However, although Physical Role had improved significantly during the study period, it did not reach the normal values of the average female population. Likewise - with the exception of Vitality - none of the mental component indicators reached normal values in the average female population during the study period. So even though improvements in the women's physical and mental health had taken place during the study period, and even though some were significant, the women's health status was still below the average female population one year after their treatment.

The invited self-referral procedure ensured patient involvement. Routine screening for needs and distress as an integral part of the follow-up would facilitate this, as it might lead to increased awareness of personal needs and opportunities. 
On a long term basis this might contribute to minimizing the persisting social inequity within cancer rehabilitation and survivorship. ${ }^{[18-20]}$

Postoperative rehabilitation takes place first and foremost in the individual woman's everyday life, not at the hospital. The analysis of the women's statements showed that by recognising and reflecting on elements of their personal illness history, and by sharing it with their relatives, the women achieved new personal insight, which also strengthened their action competencies. This aspect might be further improved if former patients were involved in the sessions.

As illustrated in the evaluation forms there are certain topics, for instance intimacy and sexuality, where there is a positive but limited outcome of attending group sessions. Since former gynecological cancer patients have a substantial symptom burden in this area, and since there is a close correlation between sexual morbidity and poorer psychological adjustment, ${ }^{[21,22]}$ individualized support must be available, too, in order to meet individual or complex problems concerning sexuality.

Compared with international aftercare models, the postoperative rehabilitation program represents a combined supportive self-care and specialised shared care intervention rather than complex care management. ${ }^{[3]}$ According to the Danish Health and Medicines Authority, approximately $70 \%$ of all cured cancer patients will experience problems in relation to survivorship, which they will be able to cope with, if they receive relevant support from relatives and healthcare professionals. Furthermore, approximately $25 \%$ may need professionally led specialised input. The remaining $5 \%$ will experience complex post-treatment problems that should be addressed by a multidisciplinary long-term intervention. ${ }^{[23]}$ If the patient participation rate is anticipated to reflect estimated rehabilitation needs, the recruitment to the postoperative rehabilitation program of $35 \%$ seems sufficient. In addition, teaching and spending time with the women and their relatives during sessions also provided the clinicians with increasing insights into their patients' perspectives on survivorship and post-treatment issues. ${ }^{[24,25]}$

In the Danish National Health Service, cancer treatment and care is free and organized in politically driven regions, and the duration of hospital stays are among the lowest in the world. Within the fast-track surgical treatment regimens, patients are hospitalized for only a single or few days in relation to major surgery or even operated in day care units. ${ }^{[26,27]}$
Solely surgically treated cancer patients are therefore at risk of having unmet needs when discharged, especially regarding their supportive care. ${ }^{[27,28]}$ During the last couple of years, the participation rate of the programs has increased (see Table 2). Increasing rates were found especially among women undergoing surgery for low stage endometrial cancer; the group of patients with the shortest hospital stays due to introduction of minimal invasive treatment procedures. We assume this tendency may reflect uncovered needs, as the ability to receive and process information will be compromised by the postoperative physical condition and the psychosocial impact of the diagnosis. ${ }^{[29]}$ If this is the case, a close consideration should be given to further integrating this type of postoperative rehabilitation in regular follow-up, which might ease the transition from hospital to self care. In order to improve long-term survival by reducing the risk of cardiovascular disease, especially in endometrial cancer, the comorbidity should be especially addressed. ${ }^{[30]}$ Consequently, referral to life style programs including physical activity, weight loss and smoking secessions should be offered to women with endometrial cancer in their local area. It is however important to be aware that if the women experience treatment-related side effects, attendance in local life style programs cannot replace specialized rehabilitation. ${ }^{[6,31]}$

\section{Conclusions}

Due to short hospitalisation, women who are surgically treated for gynecological cancer in fast-track programs are at risk of having substantial unmet needs when discharged. However, attending a postoperative rehabilitation program may improve their future health related quality of life and thus facilitate survivorship. Postoperative rehabilitation programs that provide information, physical training and supportive group sessions can be established with modest resource consumption. These programs represent supportive self-care and specialised after-treatment, which should be an integrated part of the follow-up. However, interventions must be monitored by screenings of individual needs, and tailored to meet predicted requirements.

\section{ACKNOWLEDGEMENTS}

We thank the course coordinators for distributing the questionnaires and course evaluation forms, and the participants for filling them in.

\section{Conflicts of InTEREST Disclosure}

Both authors declare no conflicts of interest. 


\section{REFERENCES}

[1] Elit L, Reade CJ. Recommendations for Follow-up Care for Gynecologic Cancer Survivors. Ob-stet Gynecol. 2015 Dec; 126(6): 1207-1214. PMid: 26551194. https://doi.org/10.1097/AOG. 0000000000001129

[2] Hellbom M, Bergelt C, Bergenmar M, et al. Cancer rehabilitation: A Nordic and European perspective. Acta Oncol. 2011 Feb; 50(2): 179-186. PMid: 21231779. https://doi.org/10.3109/028418 $6 \mathrm{X} .2010 .533194$

[3] Jefford M, Rowland J, Grunfeld E, et al. Implementing improved post-treatment care for can-cer survivors in England, with reflections from Australia, Canada and the USA. Br J Cancer. 2013 Jan 15; 108(1): 14-20. PMid: 23257892. https://doi.org/10.1038/bj c. 2012.554

[4] NORDCAN. Association of the Nordic Cancer Registries. 25.04.2014. Available from: http://www-dep.iarc.fr/NORDC AN/English/frame.asp

[5] World Health Organization. International Classification of Functioning, Disability and Health. 2011. Available from: http: //www . who. int.ez./classifications/icf/en/

[6] Jensen PT, Groenvold M, Klee MC, et al. Early-stage cervical carcinoma, radical hysterectomy, and sexual function. A longitudinal study. Cancer. 2004 Jan 1; 100(1): 97-106. PMid: 14692029. https://doi.org/10.1002/cncr. 11877

[7] Saegrov S. Health, quality of life and cancer. Int Nurs Rev. 2005 Sep; 52(3): 233-240. PMid: 16033451. https://doi.org/10.1111/j . 1466-7657.2005.00416.x

[8] Seibaek L, Petersen LK. Self-valued health in Danish women after cervix cancer surgery-A retrospective questionnaire study. Eur J Oncol Nurs. 2007 Apr; 11(2): 183-186. PMid: 16963317. https: //doi.org/10.1016/j.ejon.2006.06.006

[9] Carlsson ME, Strang PM, Nygren U. Qualitative analysis of the questions raised by patients with gynecologic cancers and their relatives in an educational support group. J Cancer Educ. 1999 Spring; 14(1): 41-46. PMid: 10328323.

[10] National Board of Health. Patient schools and group based education - a review of the litera-ture focusing on methods and effect. Copenhagen: National Board of Health; 2005.

[11] National Board of Health. Patient education - a medical technology report. 2009. Available from: http://www.sst.dk/mtv

[12] Seibaek L, Petersen LK. Nurse-led rehabilitation after gynaecological cancer surgery: preliminary results from a clinically controlled, prospective questionnaire study. Support Care Cancer. 2009 May; 17(5): 601-605. PMid: 19005688. https://doi.org/10.1007/ s00520-008-0527-9

[13] Bjoerner JB. Dansk manual til SF-36. Et spørgeskema til helbredsstatus [Danish manual for SF-36]. København: Lægemiddelindustriforeningen; 1997.

[14] Antonovsky A. The structure and properties of the sense of coherence scale. Social Science \& Medicine. 1993; 36(6): 725-733. https : //doi.org/10.1016/0277-9536(93)90033-Z

[15] Juul S. An Introduction to Stata for Health Researchers. Texas: Stata Press; 2006.

[16] Langius A. BH. Den salutogena modellen och använding av KASAMformuläret i omvårdnadsforskning - en metodredovisning. Vaard $\mathrm{i}$ Norden. 1996; 16: 28-32. PMid: 9555525. https://doi.org/10 $.1177 / 010740839601600106$

[17] Kjoeller M, Rasmussen NK. Health and morbidiy in Denmark 2000 [Sundhed og sygelighed i Danmark 2000 og udviklingen siden 1987]. Copenhagen: The Danish National Institute for Public Health; 2002.
[18] Holm LV, Hansen DG, Larsen PV, et al. Social inequality in cancer rehabilitation: a population-based cohort study. Acta Oncol. 2013 Feb; 52(2): 410-422. PMid: 23320776. https://doi.org/10.3 109/0284186X. 2012.745014

[19] Veloso AG, Sperling C, Holm LV, et al. Unmet needs in cancer rehabilitation during the early cancer trajectory-a nationwide patient survey. Acta Oncol. 2013 Feb; 52(2): 372-381. PMid: 23320774. https://doi.org/10.3109/0284186X.2012.745648

[20] Hansen DG, Larsen PV, Holm LV, et al. Association between unmet needs and quality of life of cancer patients: a population-based study. Acta Oncol. 2013 Feb; 52(2): 391-399. PMid: 23244672. https://doi.org/10.3109/0284186X.2012.742204

[21] Levin AO, Carpenter KM, Fowler JM, et al. Sexual morbidity associated with poorer psycho-logical adjustment among gynecological cancer survivors. Int J Gynecol Cancer. 2010 Apr; 20(3): 461470. PMid: 20375814. https ://doi.org/10.1111/IGC.Ob013e $3181 \mathrm{~d} 24 \mathrm{ce} 0$

[22] Barbera L, Fitch M, Adams L, et al. Improving care for women after gynecological cancer: the development of a sexuality clinic. Menopause. 2011 Sep 15. PMid: 21926930. https ://doi .org/10 .1097 /gme.0b013e31821f598c

[23] Danish Health and Medicines Authority. Program for rehabilitation and palliation of cancer [Forløbsprogram for rehabilitering og palliation i forbindelse med kræft]. Copenhagen: Danish Health and Medicines Authority; 2012.

[24] Dahl L, Wittrup I, Vaeggemose U, et al. Life after gynecologic cancer-a review of patients quality of life, needs, and preferences in regard to follow-up. Int J Gynecol Cancer. 2013 Feb; 23(2): $227-$ 234. PMid: 23314284. https://doi.org/10.1097/IGC.0b013e $31827 f 37 \mathrm{~b} 0$

[25] Dahl L, Wittrup I, Petersen LK, et al. Paradoxes of follow-up - health professionals' views on follow-up after surgical treatment in gynecological cancer. Acta Oncol. 2014 Jul; 14: 1-6.

[26] Marx C, Rasmussen T, Jakobsen DH, et al. The effect of accelerated rehabilitation on recov-ery after surgery for ovarian malignancy. Acta Obstet Gynecol Scand. 2006; 85(4): 488-492. PMid: 16612713 https ://doi.org/10.1080/00016340500408325

[27] Dinesen JGR, Hessellund B, Petersen LK. Discharge less than 6 hours after robot-assisted to-tal laparoscopic hysterectomy - is it feasible? Gynaecological Surgery. 2014; 12(1): 77-80. https : //doi.org/10.1007/s10397-014-0874-0

[28] Norlyk A, Harder I. After colonic surgery: The lived experience of participating in a fast-track programme. Int J Qual Stud Health Well-being. 2009 Sep 1; 4: 170-180. PMid: 20523886. https : //doi.org/10.1080/17482620903027726

[29] Sekse RJ, Blaaka G, Buestad I, et al. Education and counselling group intervention for women treated for gynaecological cancer: does it help? Scand J Caring Sci. 2014 Mar; 28(1): 112-121. PMid: 23317287. https://doi.org/10.1111/scs.12024

[30] McCarroll ML, Armbruster S, Frasure HE, et al. Self-efficacy, quality of life, and weight loss in overweight/obese endometrial cancer survivors (SUCCEED): a randomized controlled trial. Gynecol Oncol. 2014 Feb; 132(2): 397-402. PMid: 24369301. https: //doi.org/10.1016/j.ygyno.2013.12.023

[31] Froeding LP, Ottosen C, Rung-Hansen H, et al. Sexual functioning and vaginal changes after radical vaginal trachelectomy in early stage cervical cancer patients: a longitudinal study. J Sex Med. 2014 Feb; 11(2): 595-604. PMid: 24286464. https://doi.org/10.1111/ jsm. 12399 